\title{
Educational debts incurred by racism and sexism in students' beliefs about physics
}

\author{
Jayson Nissen \\ J. M. Nissen Consulting, Corvallis, OR, 97333, USA \\ Ben Van Dusen \\ Department of Science Education, California State University Chico, Chico, CA, 95929, USA
}

The American Physical Society calls on its members to improve the diversity of physics by supporting an inclusive culture that encourages women and people of color to become physicists. Becoming a physicist demands a set of beliefs about what it means to learn and do physics. Rather than physics courses and degree programs supporting students in developing these beliefs, evidence shows that physics education filters out students without sufficient beliefs. To better understand the role of beliefs in the lack of diversity in physics, we investigated the intersectional nature of race/racism and gender/sexism in inequities in student beliefs towards learning and doing physics using a critical quantitative intersectionality framework. The analyses used hierarchical linear models to examine students' beliefs as measured by the Colorado learning attitudes about science survey. The data came from the LASSO database and included 1248 students in 29 calculus-based mechanics courses. Like prior studies, we found that beliefs either did not change or slightly decreased for most groups. Results identified large differences across intersecting race and gender groups. White students, particularly White men, tended to have more expert-like beliefs than any other group of students. Physics instruction must address these educational debts to move toward an inclusive culture supportive of diverse students and professionals.

2019 PERC Proceedings edited by Cao, Wolf, and Bennett; Peer-reviewed, doi.org/10.1119/perc.2019.pr.Nissen Published by the American Association of Physics Teachers under a Creative Commons Attribution 4.0 license. Further distribution must maintain attribution to the article's authors, cover page, and DOI. 


\section{INTRODUCTION}

Physicists hold a distinct set of beliefs about the nature of science. These beliefs support learning $[1,2]$ and are necessary for becoming a professional physicist $[3,4]$. While most students in calculus-based mechanics courses hold a majority of these beliefs [5], they do not hold enough of the beliefs to become professional physicists. Some curriculum explicitly focused on developing beliefs about learning and doing physics support students in algebra and calculus-based introductory physics courses in developing expert beliefs. However, mounting evidence indicates that most introductory physics courses either harm or do not impact students beliefs [5]. Rather than the culture and activities of physics courses supporting students in developing these beliefs, physics education filters out students who do not arrive with the prerequisite beliefs for becoming a professional physicist [3, 4].

Many physicists believe that physics is, or should be, a meritocracy, where all students have equal opportunities to succeed and those that work hard succeed in their physics courses. Meritocracy often assumes that individuals and groups start from the same place and ignores differences in individuals and groups backgrounds. At the same time, many physicists endorse the idea that success in physics requires raw innate talent [6]. Critical Race Theory, the framework for this research, problematizes the notion of a meritocracy by pointing out that racist power structures integral to education in the United States inherently advantage White students $[7,8]$. Ladson-Billings [9] refers to these systemic differences between groups as educational debts to make explicit that they represent a failing of society and not of the students. One path to increasing diversity in physics [10] is to teach physics in a way that addresses the educational debts students from marginalized groups bear.

We explored the intersectional nature of race/racism and gender/sexism in beliefs from a large (but not representative) sample of students in calculus-based mechanics courses. Women and people of color are underrepresented in physics $[11,12]$. Being successful in the current system for preparing physicists requires a particular set of beliefs about what it means to learn and do physics. Physics courses and programs seldom generally foster students in developing these beliefs; rather, physics programs produce majors from the pool of students who already have the necessary beliefs [3-5]. If the beliefs about physics that women and students of color hold are less expert-like than those of White men, far fewer of them can become physicists in the current system. In that case, increasing diversity in physics will require developing and using pedagogies that support students in developing the beliefs they need to succeed in physics. To investigate these issues we asked the following research question:

To what extent does the intersection of race/racism and gender/sexism predict students' beliefs before and after taking calculus-based mechanics courses?

\section{FRAMEWORK}

Critical Quantitative Intersectionality (CQI) provides a framework for applying critical theory $[7,13,14]$ and intersectionality $[15,16]$, which have been used primarily for qualitative studies $[17,18]$, to quantitative studies in physics education [19]. CQI examines unique constellations of race, gender, and class social location as categories of experience in a given educational context [20]. CQI positions us to, "use data to represent educational processes and outcomes on a large scale to reveal inequities and to identify social or institutional perpetuation of systematic inequities in such processes and outcomes"; and to "question the models, measures, and analytic practices of quantitative research in order to offer competing models, measures, and analytic practices that better describe experiences of those who have not been adequately represented" [18, p. 10-11].

Quantitative research on STEM student equity often takes a neutral stance and lets the numbers speak for themselves [21]. As with our research into student learning [19], however, we take a critical perspective that problematizes power structures and their roles in perpetuating classroom and social inequities. To avoid our findings being interpreted from a deficit perspective, we often used advocative terms (e.g., gender/sexism, race/racism, and marginalized) over more neutral terms (e.g., gender, race, and underrepresented minority).

\section{METHODS}

The data for this study comes from the Colorado learning attitudes about science survey (CLASS) [22]. We accessed student and course data through the Learning About STEM Student Outcomes (LASSO) platform [23]. The LASSO platform is an online platform that collects large-scale, multi-institution data by administering, scoring, and analyzing research-based assessments. To support research, the LASSO platform makes an anonymized version of its database of student and course data available. The database only includes students who consented to share their data with researchers. The data came from 2088 students in 34 courses from 13 institutions. Thirty of the 34 courses used the Learning Assistant Model [24] and only included one two-year college.

To clean the data, we removed the pretest or posttest score if the student took less than 3 minutes on the assessment or incorrectly answered the filter question [22]. After cleaning the data, we used hierarchical multiple imputation (HMI) with the hmi [25] and mice [26] packages in R- Studio V. 1.1.456 to address missing data. HMI is a principled method for maximizing statistical power by addressing missing data while accounting for the hierarchical structure of the data [27-31]. Descriptive statistics for the imputed data are shown in Table I.

To investigate student beliefs, we developed two sets of models to predict student beliefs on the pretest and the 
TABLE I. Descriptive statistics

\begin{tabular}{llrrrrr}
\hline \hline Gender Race & \multicolumn{2}{c}{ N } & \multicolumn{2}{c}{ Pretest } & \multicolumn{2}{c}{ Post-test } \\
& & & Mean & SD & Mean & SD \\
\hline Female & Asian & 130 & 57.3 & 15.9 & 57.4 & 16.9 \\
Male & Asian & 249 & 61.0 & 15.5 & 58.7 & 18.4 \\
Female & Black & 38 & 57.6 & 14.9 & 55.1 & 15.3 \\
Male & Black & 50 & 58.8 & 15.8 & 56.3 & 19.0 \\
Female & Hispanic & 109 & 55.6 & 17.2 & 53.2 & 17.8 \\
Male & Hispanic & 358 & 61.0 & 14.5 & 58.6 & 16.9 \\
Female & other & 102 & 58.7 & 17.2 & 56.4 & 19.0 \\
Male & other & 131 & 62.4 & 15.5 & 62.6 & 15.5 \\
Female & White & 293 & 64.6 & 16.5 & 61.5 & 18.6 \\
Male & White & 628 & 66.2 & 15.6 & 64.9 & 17.1 \\
\hline \hline
\end{tabular}

posttest. We scored student's beliefs using the instrument developers scale [22]. Our models were 2-level hierarchical linear models with student data in the first level and course data in the second level. Using hierarchical linear models allowed us to account for the nested nature of our dataset [32]. We developed the models and pooled the results for the imputed datasets using the mitml [33] and lme4 [34] packages in R. We developed the models through a step-wise addition of variables. To identify the simplest model that accounted for the most variance, we only included variables that improved the student-level variance explained by at least $1 \%$. We focused on the student level variance because the course level variance was relatively small $<3 \%$ and fluctuated between models. The final models met all assumptions.

Our analysis focused on the point estimates and standard errors produced by the models. We follow the recommendations made in the American Statistical Associations special issue on moving beyond p-values because of their consistent misuse in the scientific literature [3537]. We do not present p-values because they lead to selective reporting and selective attention [37] that would ignore injustices borne by the most underrepresented and marginalized groups of students because p-values depend on sample sizes.

Our model development included variables for, gender $\left(\right.$ Female $\left._{i j}\right)$ and race $\left(\right.$ Asian $_{i j}$, Black $_{i j}$, Hispanic $_{i j}$, and other $\left._{i j}\right)$. The female group included all students that did not identify as male. This included four students that identified as trans and four students that identified as gender nonconforming. Samples this small do not provide dependable statistical results, however we included all students in the analyses because removing them could have biased course level measures. We combined them with the female students because the marginalization both groups face is rooted in sexism. Labeling the group female represented the majority of students in the group and avoided a male-centric term like non-male. We included students who did not reply to the race demographic questions, chose "a race or ethnicity not listed here", or chose a race with a small representation in the other category. The two races with low representation were Native Americans $(\mathrm{N}=1)$ and Hawaiian or Pacific
Islander $(\mathrm{N}=13)$. We included the other category in our model to maximize sample size and minimize bias at the course level but will not discuss the results for this group. The following equations describe the final models.

\section{Level-1 Equations (Student-level)}

$$
\begin{aligned}
\text { Score }_{i j}= & \beta_{0 j}+\beta_{1 j} *\left(\text { Female }_{i j}\right)+\beta_{2 j} *\left(\text { Asian }_{i j}\right)+ \\
& \beta_{3 j} *\left(\text { Black }_{i j}\right)+\beta_{4 j} *\left(\text { Hispanic }_{i j}\right)+ \\
& \beta_{5 j} *\left(\text { other }_{i j}\right)+\beta_{6 j} *\left(\text { FemaleX Asian }_{i j}\right)+ \\
& \beta_{7 j} *\left(\text { FemaleX Black }_{i j}\right)+ \\
& \beta_{8 j} *\left(\text { FemaleX Hispanic }_{i j}\right)+ \\
& \beta_{9 j} *\left(\text { FemaleXother }_{i j}\right)+r_{i j}
\end{aligned}
$$

\section{Level-2 Equations (Course-level)}

$$
\beta_{i j}=\gamma_{i 0}
$$

To create an effect size of any racial and gender differences we identified, we drew on the literature to establish a reasonable cutoff in expert beliefs necessary for students to pursue a graduate degree and become a professional physicist. Based on Gire et al. [3] and Bates et al. [4] we estimated that professional physicists score about an $85 \%$ on the CLASS on average with a standard deviation of approximately $10 \%$. Given that students do not tend to improve their beliefs about physics through their undergraduate education [3,4], we settled on $75 \%$ as an estimate for the beliefs that a student needs to start college with to have a reasonable chance of becoming a physicist. This $75 \%$ cutoff is not definitive for the minimum beliefs to become a physicist. Rather, we use it to illustrate the potential effects of racial disparities in physics beliefs on diversifying physics. We present density plots of posttest beliefs by race and descriptive statistics by race and gender to illustrate the difference in proportion of students from each race and gender with the beliefs to become physicists.

\section{FINDINGS AND DISCUSSION}

Table II details the final models for pretest and posttest with point estimates and standard errors presented in Fig. 1. The models showed small decreases in beliefs from pretest to post-test for White, Hispanic, and Black students and no shifts for Asian students. These results align with prior findings that student beliefs decreased in most physics courses, even those that used active engagement [5]. Taking into account the standard error, the models indicated that women of color (Asian, Black, and Hispanic women who are all marginalized by both sexism and racism) tended to have similar beliefs and that men of color tended to have similar beliefs. The models also indicated that on average White men's and White women's beliefs differed from each other and from both men and women of color. 


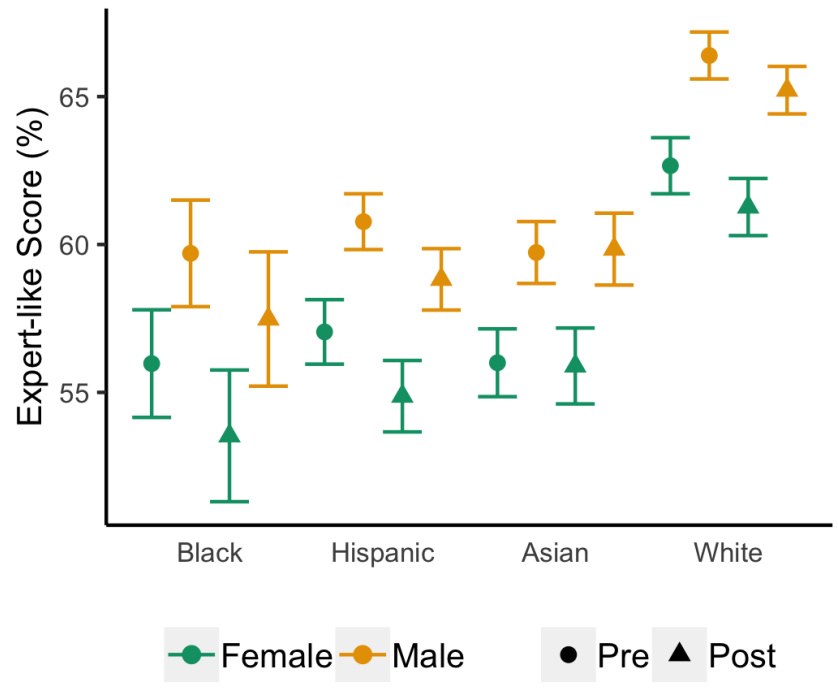

FIG. 1. Predicted beliefs for pretest and post-test beliefs disaggregated by race and gender as measured by the CLASS. The point estimates show large differences in beliefs favoring male and White students and show little change from pretest to post-test. Error bars represent one standard error.

Women of color reported the least expert beliefs of any group followed by men of color. The error bars for these two groups of students indicated that the model did not precisely fit the data for both Black men and Black women. Black women may tend to have lower scores than other women of color and Black men may tend to have scores more similar to Hispanic and Asian women than to other men of color. The inability of the models to precisely locate the point estimates for Black men and women results more from the small number of Black students in the sample than from a larger variation in their beliefs (Table I). White women reported beliefs that tended to be lower than White men and slightly higher than men of color. White men reported the most expert beliefs on average.

The models indicated an intersectional approach was necessary for investigating beliefs. Beliefs varied by both race and gender. Furthermore, researchers often combine Asian students with White students because both groups are overrepresented in physics. However, our models found that Asian students hold beliefs more similar to other students of color than to White students.

Figure 2 shows the density plots for students post-test beliefs. The dashed red line represents the $75 \%$ cutoff estimated for becoming a professional physicist we discussed in the methods. The area under the curve to the right of the dashed red line represents the likelihood of a student from each race having beliefs necessary to become a physicist. White students were the most likely to have these beliefs (26\%) followed by Asian (14\%), Hispanic (14\%), and Black (10\%) students. These results show a large racial/racist inequity in that Asian,
TABLE II. Hierarchical Linear Models.

\begin{tabular}{lrrrr}
\hline \hline & \multicolumn{2}{c}{ Pretest } & \multicolumn{2}{r}{ Post-test } \\
Coefficient & $\beta$ & $\mathrm{SE}$ & $\beta$ & $\mathrm{SE}$ \\
\hline Intercept & 66.0 & 0.84 & 65.2 & 0.87 \\
Female & -2.4 & 1.17 & -3.8 & 1.34 \\
Asian & -5.9 & 1.24 & -6.1 & 1.48 \\
Black & -7.3 & 2.33 & -9.0 & 2.93 \\
Hispanic & -4.6 & 1.07 & -6.0 & 1.28 \\
other & -3.3 & 1.56 & -2.0 & 1.83 \\
Fem. X Asian & -2.3 & 2.13 & 2.0 & 2.60 \\
Fem. X Black & -1.2 & 3.69 & 2.9 & 4.09 \\
Fem. X Hispanic & -3.7 & 2.08 & -1.7 & 2.40 \\
Fem. X other & -1.9 & 2.45 & -2.8 & 2.96 \\
\hline \hline
\end{tabular}

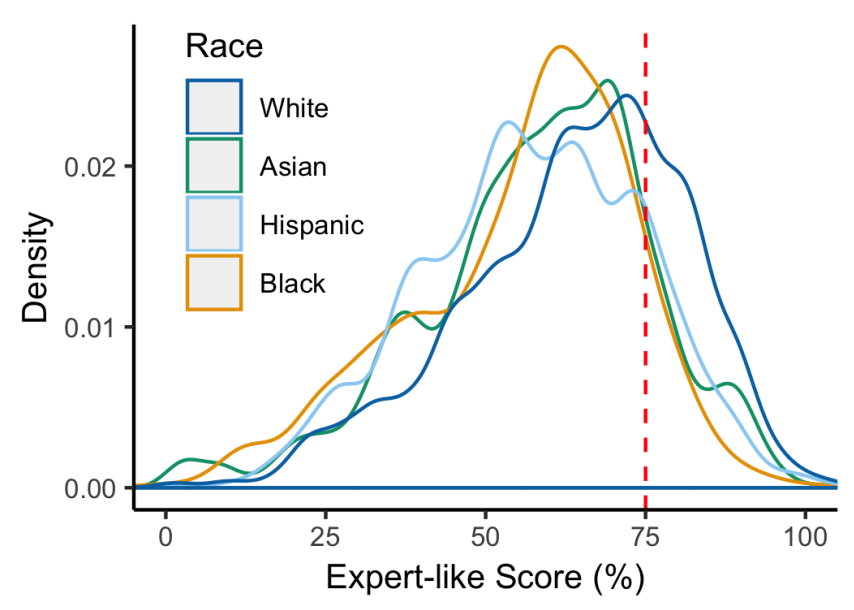

FIG. 2. Density plots of the posttest beliefs by race. The red line indicates the $75 \%$ cutoff for estimated beliefs necessary to pursue and receive a graduate degree in physics. The density plots show inequities in students beliefs that may contribute to the lack of diversity in physics.

Hispanic, and Black students education failed to provide them with the opportunities to develop the beliefs necessary to become a professional physicist.

The density plots are only disaggregated by race for simplicity. Table III extends the information presented in the density plots by providing the percentage of students from each intersectional group that reported beliefs sufficient to become professional physicists. These race/racist and gender/sexist inequities are even starker than those presented in the density plots as very few women of color report CLASS scores greater than $75 \%$. Few women of color overcome the educational debt owed them to take calculus-based mechanics courses. Subsequently, these sexist and racist inequities in beliefs mean that even fewer women of color have the opportunity to become physicists. 
TABLE III. The percentage of each intersectional group with sufficient beliefs to become a professional physicist.

\begin{tabular}{lrr}
\hline \hline & \multicolumn{2}{c}{$\%>75$} \\
Race & Female & Male \\
\hline Asian & $11 \%$ & $16 \%$ \\
Black & $3 \%$ & $16 \%$ \\
Hispanic & $9 \%$ & $15 \%$ \\
White & $22 \%$ & $28 \%$ \\
\hline \hline
\end{tabular}

\section{CONCLUSION}

Our findings illustrated large educational debts owed to women and students of color in terms of beliefs about learning and doing physics. The educational debt owed women is consistent with a lack of early educational experiences in the sciences playing a role in the underrepresentation of women in physics [38]. These differences in physics beliefs do not represent deficiencies in the students themselves; rather, they represent a lifetime of science and math experiences catered to White male students. By failing to address the educational debt owed to both women and students of color, physics education perpetuates the racist and sexist power structures that created those debts.

These results show the practice of grouping Asian and White students may obscure inequities between White students and students of color. Society enacts racism against Asian Americans through both the model minority stereotype [39] and by ignoring diversity across the ethnicities that make up Asian Americans [17, 39, 40]. The model minority stereotype portrays Asian Americans as a monolithic, hardworking and successful group and is used to undermine Black Americans claims of racism in the United States. Asian Americans are a panethnic racial group that is represented at higher rates in many science and technology disciplines at higher rates than they are in the U.S. population. However, Asian Americans academic attainment correlates with their class status [40] and varies across ethnic groups [17]. One possible explanation for the difference between the attitudes of White and Asian American students in this study is that the students in our sample of introductory physics courses from 13 institutions represents a more diverse group of students than those who earn undergraduate degrees in physics. Future work can better inform the racism and classism Asian Americans experience in their physics education by accounting for both ethnicity and socioeconomic status. We recommend that researchers provide empirical support for combining Asian and White student populations in their study. Doing otherwise risks minimizing the measurements of racism in future studies and perpetuates the harmful model minority stereotype. The LASSO data used in this study adopted common demographic measures in physics education research and did not disaggregate across Asian ethnicities, however the demographics questions have been changed to collect this information.

Our data do not represent the breadth of calculusbased mechanics courses and therefor limits the generalizability of our findings. Only one institution in the data set was a two-year college, but a large portion of college physics courses are taken at two-year colleges [41]. Future work should explore issues of beliefs and equity across the intersection of race and gender in the two-year college environment. Similarly, research should seek to replicate findings of pedagogies that support students in developing their beliefs at two-year colleges.

The American Physical Society (APS) statement on diversity [10] takes a strong stance on creating systems that support the success of students from diverse background. In it they, "call upon policymakers, administrators, and managers at all levels to enact policies and promote budgets that will foster greater diversity in physics. ... We call upon the physics community as a whole to work collectively to bring greater diversity wherever physicists are educated or employed." If few women and students of color have the beliefs that the physics community requires to become a professional physicist and physics instruction continues to not support students in developing these beliefs, physics will not become more diverse. Pedagogies with an epistemilogical or model-based focus can support students in developing the beliefs necessary for becoming a physicist [5]. In particular, Traxler and Brewe [42] found Modeling Instruction supports women and students of color in developing more expert-like beliefs. Meeting the call of the APS requires researchers to confirm these results in other settings and to further identify the mechanisms by which they support students changing their beliefs. Meeting this call will also require faculty and instructors demanding the resources to implement evidence-based pedagogies that support diverse students in developing expert beliefs. In pursuing equity, Critical Race Theory warns that interventions to support women and students of color will only be implemented when they benefit the group in power, White men, thereby creating an interest convergence. The physics community should attend to which institutions and which students receive resources to improve diversity in physics, and the physics education research community should attend to which institutions and students are represented in our investigations of these interventions.

\section{ACKNOWLEDGEMENTS}

We are grateful to the Learning Assistant Program at the University of Colorado Boulder for establishing the LASSO platform. This work is funded in part by NSFIUSE Grant No. DUE-1525338 and is Contribution No. LAA-065 of the Learning Assistant Alliance. 
[1] L. Ding, "Verification of causal influences of reasoning skills and epistemology on physics conceptual learning," Physical Review Special Topics - Physics Education Research 10, 023101 (2014).

[2] K. K. Perkins, W. K. Adams, S. J. Pollock, N. D. Finkelstein, and C. E. Wieman, "Correlating student beliefs with student learning using the colorado learning attitudes about science survey," in AIP Conference Proceedings, Vol. 790 (AIP, 2005) pp. 61-64.

[3] E. Gire, B. Jones, and E. Price, "Characterizing the epistemological development of physics majors," Physical Review Special Topics - Physics Education Research 5, 010103 (2009).

[4] S. P. Bates, R. K. Galloway, C. Loptson, and K. A. Slaughter, "How attitudes and beliefs about physics change from high school to faculty," Physical Review Special Topics - Physics Education Research 7, 020114 (2011).

[5] A. Madsen, S. B. McKagan, and E. C. Sayre, "How physics instruction impacts students beliefs about learning physics: A meta-analysis of 24 studies," Physical Review Special Topics-Physics Education Research 11, 010115 (2015).

[6] S. J. Leslie, A. Cimpian, M. Meyer, and E. Freeland, "Expectations of brilliance underlie gender distributions across academic disciplines," Science 347, 262265 (2015).

[7] G. Ladson-Billings and W. F. Tate, "Toward a critical race theory of education," Teachers College Record 97, 47 (1995).

[8] J. J. Park and A. Liu, "Interest convergence or divergence? A critical race analysis of Asian Americans, meritocracy, and critical mass in the affirmative action debate," The Journal of Higher Education 85, 36-64 (2014).

[9] Gloria Ladson-Billings, "From the achievement gap to the education debt: Understanding achievement in us schools," Educational Researcher 35, 3-12 (2006).

[10] American Physical Society, "Diversity Statement," (2018).

[11] American Institute of Physics, "Percent of Physics Bachelor's Degrees Earned by Women, Classes of 1981 through 2010," (2012).

[12] American Institute of Physics, "Minority Physics Statistics," (2019).

[13] G. Ladson-Billings, "Its your world, im just trying to explain it: Understanding our epistemological and methodological challenges," Qualitative Inquiry 9, 5-12 (2003).

[14] C. E. Sleeter and D. D. Bernal, "Critical pedagogy, critical race theory, and antiracist education: Implications for multicultural education," Handbook of Research on Multicultural Education 2, 240-258 (2004).

[15] K. Crenshaw, "Mapping the margins: Intersectionality, identity politics, and violence against women of color," Standard Legal Review 43, 1241 (1990).

[16] P. H. Collins and S. Bilge, Intersectionality (John Wiley \& Sons, 2016).

[17] S. T. Jang, "The implications of intersectionality on southeast Asian female students educational outcomes in the United States: A critical quantitative intersectionality analysis," American Educational Research Journal
55, 1268-1306 (2018).

[18] F. K. Stage, "Answering critical questions using quantitative data," New Directions for Institutional Research 2007, 5-16 (2007).

[19] B. Van Dusen and J. M. Nissen, "The state of equity in college physics student learning: a critical quantitative intersectionality investigation," Journal of Research in Science Teaching (In Press).

[20] N. López, C. Erwin, M. Binder, and M. J. Chavez, "Making the invisible visible: Advancing quantitative methods in higher education using critical race theory and intersectionality," Race Ethnicity and Education 21, 180-207 (2018).

[21] A. Covarrubias, "Quantitative intersectionality: A critical race analysis of the Chicana/o educational pipeline," Journal of Latinos and Education 10, 86-105 (2011).

[22] Wendy K. A., K. K. Perkins, N. S. Podolefsky, M. Dubson, N. D. Finkelstein, and C. E. Wieman, "New instrument for measuring student beliefs about physics and learning physics: The colorado learning attitudes about science survey," Physical Review Special Topics - Physics Education Research 2, 010101 (2006).

[23] B. Van Dusen, "Lasso: A new tool to support instructors and researchers," American Physics Society Forum on Education Fall 2018 Newsletter (2018).

[24] V. Otero, S. Pollock, and N. Finkelstein, "A physics departments role in preparing physics teachers: The colorado learning assistant model," American Journal of Physics 78, 1218-1224 (2010).

[25] M. Speidel, J. Drechsler, and S. Jolani, hmi: Hierarchical Multiple Imputation (2018), r package version 0.9.13.

[26] S. van Buuren and K. Groothuis-Oudshoorn, "mice: Multivariate imputation by chained equations in r," Journal of Statistical Software 45, 1-67 (2011).

[27] P. D. Allison, Missing data, Vol. 136 (Sage publications, 2001).

[28] E. R. Buhi, P. Goodson, and T. B. Neilands, "Out of sight, not out of mind: strategies for handling missing data," American Journal of Health Behavior 32, 83-92 (2008).

[29] J. L. Schafer, "Multiple imputation: a primer," Statistical Methods in Medical Research 8, 3-15 (1999).

[30] C. A. Manly and R. S. Wells, "Reporting the use of multiple imputation for missing data in higher education research," Research in Higher Education 56, 397409 (2015).

[31] J. M. Nissen, R. Donatello, and B. Van Dusen, "Missing data and bias in physics education research: A case for using multiple imputation," Physical Review Physics Education Research (In Press).

[32] B. Van Dusen and J. M. Nissen, "Modernizing use of regression models in physics education research: a review ofhierarchical linear modeling," Physical Review Physics Education Research (In Press).

[33] S. Grund, A. Robitzsch, and O. Luedtke, mitml: Tools for Multiple Imputation in Multilevel Modeling (2018), $\mathrm{r}$ package version 0.3-6.

[34] D. Bates, M. Mächler, B. Bolker, and S. Walker, "Fitting linear mixed-effects models using lme4," Journal of Statistical Software 67, 1-48 (2015). 
[35] R. L. Wasserstein, N. A. Lazar, et al., "The ASA's statement on p-values: context, process, and purpose," The American Statistician 70, 129-133 (2016).

[36] R. L. Wasserstein, A. L. Schirm, and N. A. Lazar, "Moving to a world beyond "p $<0.05 "$, , (2019).

[37] V. Amrhein, D. Trafimow, and S. Greenland, "Inferential statistics as descriptive statistics: There is no replication crisis if we dont expect replication," The American Statistician (2018).

[38] S. Cheryan, S. A. Ziegler, A. K. Montoya, and L. Jiang, "Why are some stem fields more gender balanced than others?" Psychological Bulletin 143, 1 (2017).

[39] OiYan Poon, Dian Squire, Corinne Kodama, Ajani Byrd, Jason Chan, Lester Manzano, Sara Furr, and Devita
Bishundat, "A critical review of the model minority myth in selected literature on asian americans and pacific islanders in higher education," Review of Educational Research 86, 469-502 (2016).

[40] Alejandro Covarrubias and Daniel D Liou, "Asian american education and income attainment in the era of postracial america." Teachers College Record (2014).

[41] S. Kanim and X. Cid, "The demographics of physics education research," Physical Review Physics Education Research (In Review).

[42] A. Traxler and E. Brewe, "Equity investigation of attitudinal shifts in introductory physics," Physical Review Special Topics-Physics Education Research 11, 020132 (2015). 